\title{
A multistage approach to blood conservation in a Jehovah's Witness patient undergoing redo aortic arch surgery
}

\author{
Rahul Basu, Surendra Naik, Mohammad Shafaat, John Lu* \\ From World Society of Cardiothoracic Surgeons 25th Anniversary Congress, Edinburgh \\ Edinburgh, UK. 19-22 September 2015
}

\section{Background/Introduction}

49 year old woman with Marfan's syndrome previously treated with aortic root replacement and resuspension of aortic valve for type A dissection. Now presented with progressive dilating $6.3 \mathrm{~cm}$ arch aneurysm requiring redo surgery.

\section{Aims/Objectives}

To describe a multi-stage approach of patient blood management in a Jehovah's Witness undergoing redo aortic arch surgery.

\section{Method}

Preoperative phase

Baseline ferritin, transferrin, B12, folate and TFT levels.

Intravenous iron $1000 \mathrm{mg}$ as single dose 3-5 weeks before planned surgery.

Epoetin alfa (600 units per $\mathrm{kg}$ ) at weekly intervals starting 3 weeks before surgery and the 4th dose given day before surgery.

$\mathrm{Hb}$ improved from 119 to $152 \mathrm{~g} / \mathrm{l}$.

Perioperative phase

Predonation of 2 units blood at induction.

Usage of aprotinin.

Near normothermic CPB at $30^{\circ} \mathrm{C}$.

Usage of Hemosep ${ }^{\circledR}$ device to recover blood spilled during surgery. This preserved platelets, white and red cells for subsequent transfusion.

Postoperative phase

$\mathrm{Hb} 103 \mathrm{~g} / \mathrm{l}$ immediately post-op but fell to $64 \mathrm{~g} / \mathrm{l}$ over $24 \mathrm{~h}$. Therefore ventilated electively for 2 days giving IV iron and erthropoietin at day 1 and 4 to enhance erythropoiesis.

Patient extubated when $\mathrm{Hb} 79 \mathrm{~g} / \mathrm{l}$.

\section{Results}

Patient had no re-exploration for bleeding or tamponade. She had a period of CVVH for renal failure and IV antibiotic for chest infection.

She was transferred to the ward on day 9 and discharged home on day 13. Subsequent follow up at week 1 and 6 post discharge showed the patient doing well.

\section{Discussion/Conclusion}

Meticulous multidisciplinary individualised patient blood management can result in safe and excellent outcome in a Jehovah's Witness patient undergoing major redo aortic surgery.

\section{Consent}

Written informed consent was obtained from the patient for publication of this abstract and any accompanying images. A copy of the written consent is available for review by the Editor of this journal.

Published: 16 December 2015

doi:10.1186/1749-8090-10-S1-A99

Cite this article as: Basu et al: A multistage approach to blood conservation in a Jehovah's Witness patient undergoing redo aortic arch surgery. Journal of Cardiothoracic Surgery 2015 10(Suppl 1):A99. 